\title{
Disección de la arteria vertebral en niños, manifestada radiológicamente como signo de la llave inglesa
}

\section{Dissection of the Vertebral Artery in Children, Radiologically Manifested as the Wrench Sign}

\author{
María Florencia Muñoz Ferragut ${ }^{1,2}$ Francisco Ramón Maldonado ${ }^{3}$ Paula Andrea Alonso ${ }^{3}$ \\ Juan Pablo Princich ${ }^{3}$ Flavio Requejo ${ }^{4}$ Carlos Adrián Rugilo ${ }^{5}$
}

${ }^{1}$ Servicio de Radiología pediátrica, Clínica Universitaria Reina Fabiola, Córdoba, Argentina

${ }^{2}$ Servicio de Radiología pediátrica, Clínica Maternidad del Sol, Córdoba, Argentina

3 Servicio de Neurorradiología, Hospital de Pediatría Juan P. Garrahan, Buenos Aires, Argentina

${ }^{4}$ Servicio de Intervencionismo pediátrico, Hospital de Pediatría Juan P. Garrahan, Buenos Aires, Argentina

${ }^{5}$ Departamento de Resonancia Magnética, Hospital de Pediatría Juan P. Garrahan, Buenos Aires, Argentina

Rev Argent Radiol 2018;82:98-100.

La disección de la arteria vertebral (DAV), al igual que otras disecciones arteriales, es el resultado del pasaje de sangre hacia el espesor parietal arterial a través de un desgarro en la íntima. Es potencialmente letal y puede ser difícil de diagnosticar clínica y radiológicamente. En pediatría es más prevalente en el sexo masculino, con una media de aparición a los 9 años. ${ }^{1}$

Las DAV pueden ser espontáneas (con una incidencia que oscila entre 1 y 1,5 sobre 100.000) o traumáticas (presentes en el $0,08-0,4 \%$ del total de la población que ha sufrido un trauma). ${ }^{2}$ Las espontáneas pueden tener o no una causa subyacente, aunque entre las más frecuentes en niños se destacan las enfermedades del tejido conectivo (como la enfermedad de Ehlers-Danlos y la enfermedad de Marfan), la osteogénesis imperfecta y la displasia fibromuscular, entre otras. ${ }^{3}$ En el caso de las DAV traumáticas, es posible observarlas ante accidentes de tránsito (principalmente si se asocian a fracturas cervicales), así como a movimientos bruscos del cuello (tos, vómitos, deportes, quiropraxia, etc.) o maltrato infantil. ${ }^{4}$

En la formación de las DAV si la sangre penetra entre las capas vasculares íntima y media, se produce una estenosis luminal, que puede progresar a oclusión; mientras que si lo hace entre las capas media y adventicia, es posible que se genere un pseudoaneurisma. Ambas situaciones son factores
Address for correspondence María Florencia Muñoz Ferragut, Residente en Urología, Rosario de Santa Fé 960. Piso 4to. Dpto A., Cordoba, Argentina (e-mail: florenciamunozferragut@gmail.com).

de riesgo para la formación de émbolos y hemorragias (esto último es más frecuente cuando el segmento vertebral afectado es el intracraneal). ${ }^{3,5}$

Su presentación clínica es muy variada, desde dolor cervical y cefalea (por lo general occipital) a eventos isquémicos en fosa posterior y/o regiones occipitales, que pueden causar hemianopsia, náuseas, ataxia, disartria, síndrome medular lateral o posterior e incluso, colapso y coma. La extensión intradural es relativamente común y se asocia con hemorragia subaracnoidea. ${ }^{6}$

Las modalidades de imagen para el diagnóstico incluyen angioresonancia magnética (ARM), angiotomografía computada (ATC) y angiografía digital (AD). La ARM tiene una tasa de detección relativamente baja con una alta tasa de falsos positivos, pero ha evidenciado una alta sensibilidad en la identificación de pequeños focos isquémicos. ${ }^{6}$ La ATC por su parte, muestra una sensibilidad del $86 \%$ al $100 \%$ y una especificidad del $89 \%$ al $100 \%$. Sin embargo, tradicionalmente la $\mathrm{AD}$ ha sido el método de referencia. Demuestra la dilatación focal o fusiforme y la estenosis proximal o distal, además de que permite su tratamiento mediante técnicas de repermeabilización. ${ }^{4}$

El objetivo de este trabajo es presentar un nuevo signo radiológico para el diagnóstico de DAV. received January 31, 2017

accepted

July 7, 2017

published online

March 23, 2018
DOI https://doi.org/

$10.1055 / \mathrm{s}-0038-1637724$.

ISSN 1852-9992.
Copyright ( 2 2019, Sociedad Argentina de Radiología. Publicado por Thieme Revinter Publicações Ltda., Rio de Janeiro, Brazil. Todos los derechos reservados.

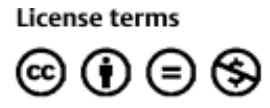




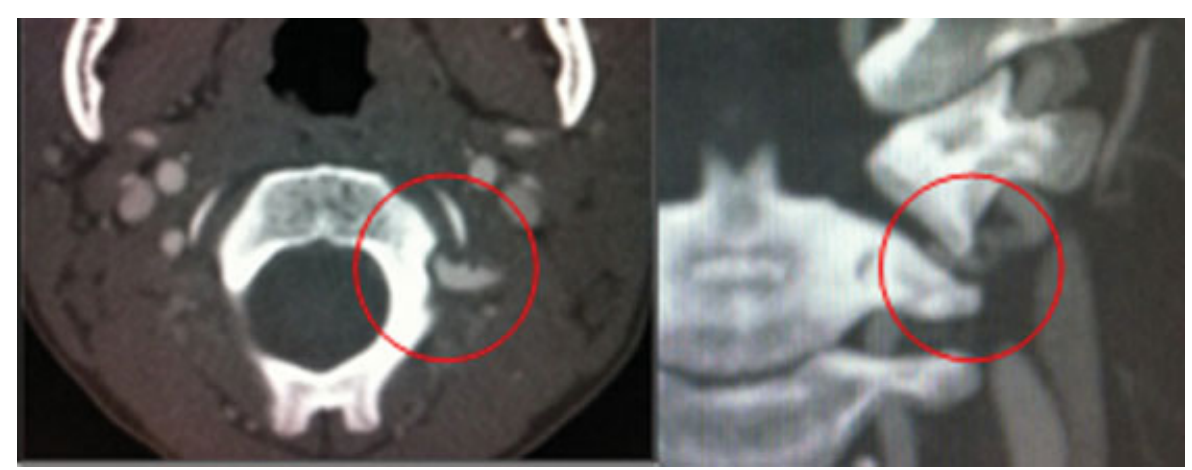

Fig. 1 Paciente de 11 años que debutó con cefalea occipital y mareos. Angiotomografía corte axial y coronal donde se visualiza irregularidad mural con morfología del signo de la llave inglesa en la porción horizontal del segmento V3 de la arteria vertebral izquierda (círculos).

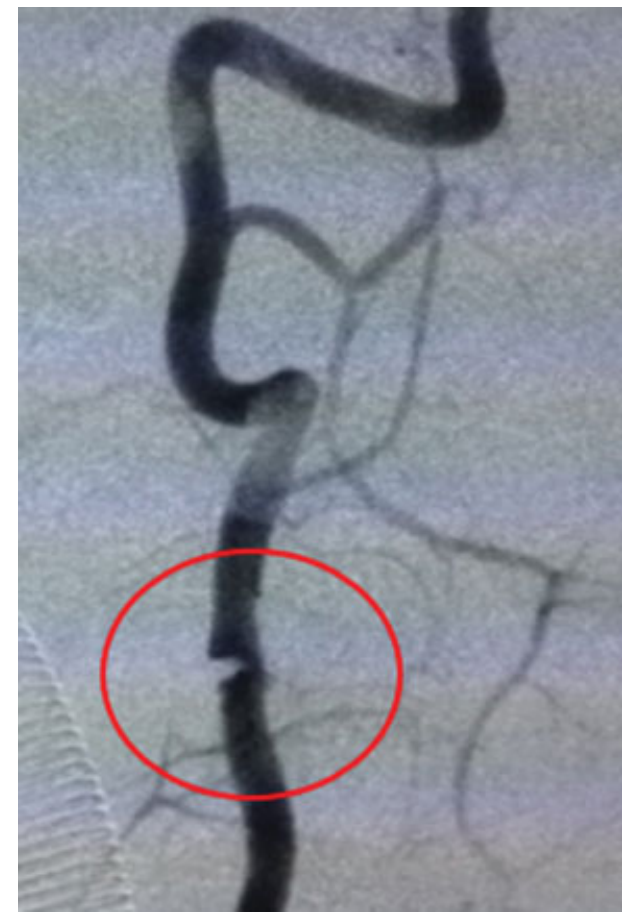

Fig. 2 Paciente de 14 años con múltiples episodios sincopales en los últimos meses. Angiografía digital en la que se observa la similitud entre la llave inglesa y la disección focal de la arteria vertebral derecha (círculo).
La mayor parte de las DAV se generan en los segmentos V2-V3 ${ }^{1}$ y los hallazgos imagenológicos clásicos descritos en la bibliografía incluyen:

- Signo de la diana o doble luz: presencia de dos luces en el interior del vaso, una constituida por el hematoma intramural semilunar y otra por la fracción de luz permeable.

- Visualización del colgajo (flap) de la íntima intraluminal lineal.

- Signo de la cuerda: estrechamiento gradual y segmentario.

- Visualización de pseudoaneurisma: dilatación segmentaria del vaso.

- Presencia de infartos embólicos secundarios en el territorio vértebro-basilar. ${ }^{5}$

Esos signos fueron descritos tanto en niños como en adultos. A partir de nuestra experiencia y luego de una revisión imagenológica, presentamos tres casos pediátricos de DAV, en los que notamos que las imágenes suelen presentarse con un patrón focal y segmentario que genera una imagen similar a la de una llave inglesa (wrench). Por ello, consideramos de utilidad tener en cuenta este nuevo signo, denominado "de la llave inglesa" o wrench sign, en relación con las DAV pediátricas (-Figs. 1-4).

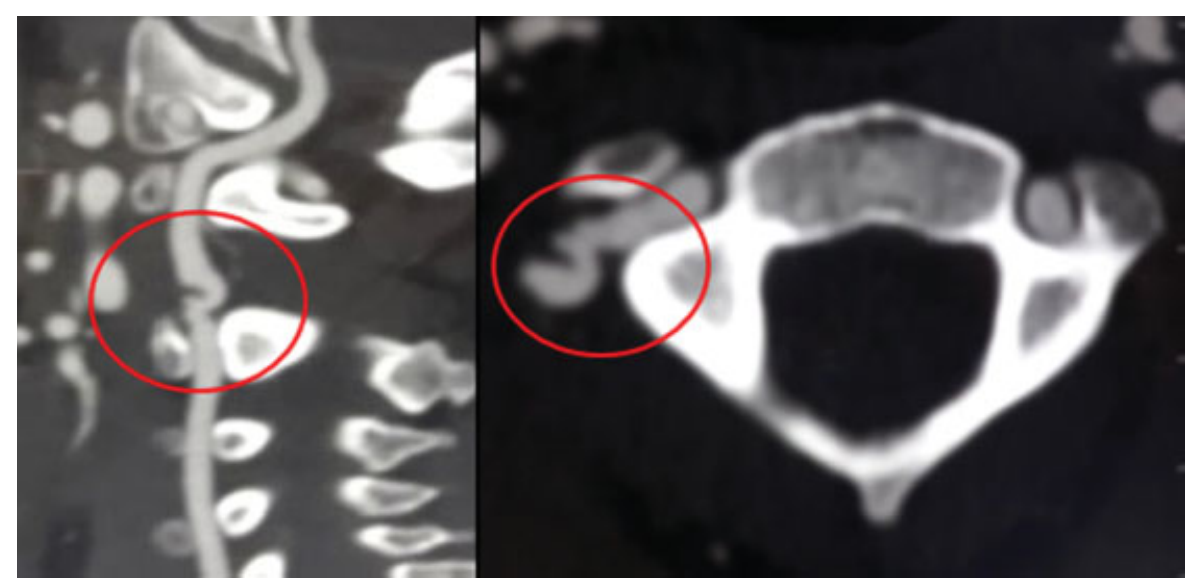

Fig. 3 Paciente de 7 años que ingresó a la guardia por vómitos y ataxia presenta una angiotomografía, en corte sagital y axial, con defecto de relleno parietal focal en la arteria vertebral derecha (círculos). 


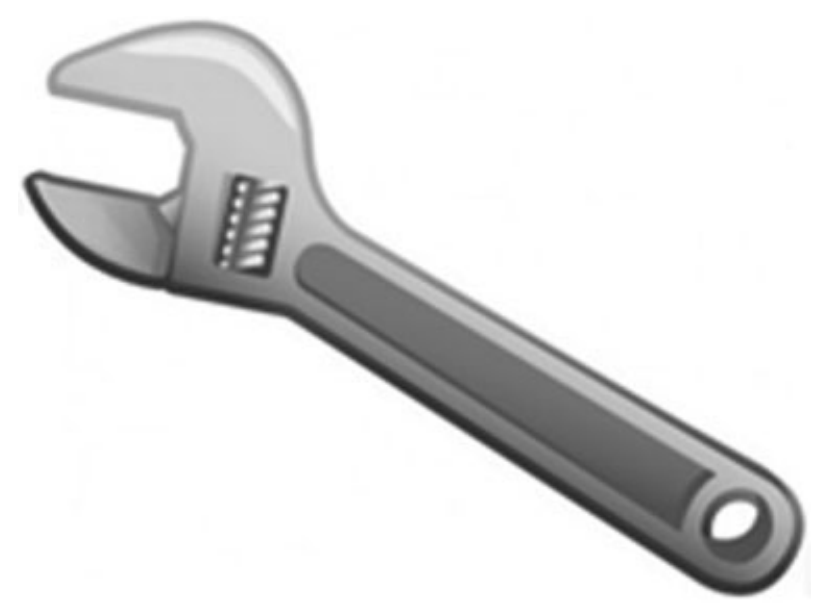

Fig. 4 Imagen de llave inglesa. Nótese la similitud entre las imágenes visualizadas anteriormente y esta herramienta.

La fisiopatogenia del frecuente patrón focal de las DAV, que origina esa morfología de llave inglesa en la infancia, es desconocida. Probablemente se deba a una distribución diferente y a una menor cantidad de fibras elásticas en la arteria vertebral, en comparación con los vasos sanguíneos de tamaño similar de otras localizaciones (aunque la túnica media y la túnica adventicia están presentes, la gran mayoría de las fibras elásticas se sitúan en una lámina elástica subendotelial). ${ }^{1,7}$ Además, otra diferencia que puede contribuir al desarrollo de esta peculiar característica imagenológica, es la alta tasa de traumatismos cráneocervicales leves que pasan desapercibidos en los niños debido a que sus estructuras osteocartilaginosas son relativamente más móviles y flexibles que las de los adultos. De todos modos, este punto abre las puertas para la realización de más investigaciones.

En conclusión, el signo de la llave inglesa o wrench sign resulta un método de imagen confiable que podría ayudar al diagnóstico de las DAV en pediatría. Teniendo en cuenta que esta patología continua siendo subdiagnosticada especialmente en niños, este signo podría ayudar a su detección y eventual tratamiento, modificando el pronóstico del paciente.

\section{Confidencialidad de los datos}

Los autores declaran que han seguido los protocolos de su centro de trabajo sobre la publicación de datos de pacientes y que todos los pacientes incluidos en el estudio han recibido información suficiente y han dado su consentimiento informado por escrito.

Conflicto de intereses

Los autores declaran no tener ningún conflicto de intereses.

\section{Bibliografía}

1 Fiz-Pérez L, Velázquez-Fragua R, García-Guixot S, García-Romero M, Martínez-Bermejo A. Diseccion de arterias vertebrales como causa de evento cerebrovascular agudo en niños. Rev Neurol 2016;62(08):382-383

2 Mortazavi MM, Verma K, Tubbs RS, Harrigan M. Pediatric traumatic carotid, vertebral and cerebral artery dissections: a review. Childs Nerv Syst 2011;27(12):2045-2056

3 Pandey AS, Hill E, Al-Holou WN, et al. Management of pediatric craniocervical arterial dissections. Childs Nerv Syst 2015;31(01): 101-107

4 Cullacciati Asi A, Arenaza Choperena G, Aguirre Oteiza M, Gurrutxaga Agirrezabalaga A, Arantzeta Lexarreta J. Lesiones traumáticas de arteria vertebral: cuando sospecharlas y cómo diagnosticarlas. SERAM. 2014; S1357. Disponible en: http://dx. doi.org/10.1594/seram2014/S-1357

5 Gary M, Nesbit MD. Disección extracraneal traumática. En: Osborn A, Salzman K, Barkovich A, Katzman G, Provenzale J, Harnsberger H, eds. Diagnóstico por Imagen Cerebro. Madrid: Marbán; 2011:70-73

6 Gui L, Shi GS, Li GJ, et al. Spontaneous vertebral artery dissection: report of 16 cases. Neurol India 2010;58(06):869-874

7 Kristoffersen S, Vetti N, Morild I. Traumatic dissection of the vertebral artery in a toddler following a short fall. Forensic Sci Int 2012;221(1-3):e34-e38 